\title{
EDITORIAL
}

\section{A polêmica instituída entre ensino de evolução e criacionismo: dimensões do público e do privado no avanço do neoconservadorismo}

A escrita deste texto se dá em meio a muitos acontecimentos graves de ordem política e educacional que vêm provocando tensões e indignação entre diversos segmentos sociais, mormente a comunidade educacional brasileira, na qual se inclui o campo de Educação em Ciências. Dentre eles, subtrações a conquistas sociais no âmbito da educação, da ciência e da tecnologia balançam a confiança nos caminhos democráticos do país, materializadas pela desconstrução do Conselho Nacional de Educação (por vias que rompem com as consultas às comunidades educacionais e associações científicas); o desmonte do Ministério de Ciência, Tecnologia e Inovação; o fechamento de secretarias do Ministério da Educação (que desempenhavam valoroso papel no cenário educacional); a Medida Provisória que reforma o Ensino Médio e atinge frontalmente a formação docente (que restitui o autoritarismo que nos parecia pertencente aos anos de chumbo); a PEC 241 (que prenuncia duas décadas de obscurantismo e ameaça os direitos à vida e à educação); e outros tantos atos que surpreendem a população e deixam perplexa a intelectualidade não só do Brasil, ao resvalar para comparações impensáveis em outros regimes democráticos. Tratar de todos esses descaminhos seria impossível neste editorial. Entretanto, é inegável que todos eles exibem as interfaces políticas referendadas em valores que se distanciam de lutas históricas por equidade e justiça. Tais descaminhos espalharam pelas páginas de nossa história a opressão e o sofrimento decorrente do sacrifício de tantas vidas.

$\mathrm{Na}$ esteira dessa onda avassaladora que coloca em xeque os valores democráticos, o Projeto de Lei 867/2015 (e seus correlatos), que inclui, entre as diretrizes e bases da educação nacional, o "Programa Escola Sem Partido" expõe uma conexão com o ensino de Ciências e Biologia na escola, pois afeta diretamente a liberdade docente e oprime o ambiente da sala de aula. Refiro-me, especialmente, ao ensino dos conteúdos biológicos escolares sustentados pela compreensão da evolução biológica em bases neodarwinistas, temática nada trivial por mostrar seu enraizamento epistemológico a uma teoria científica de maior significação para as Ciências Biológicas. O ensino de evolução na escola encontra-se ameaçado pelo curso da aprovação desse projeto de lei (em percursos difamatórios, inclusive à obra de Paulo Freire) que deseja

\footnotetext{
${ }^{1}$ Disponível em: <http://www.camara.gov.br/sileg/integras/1317168.pdf>. Acesso em: 6 out. 2016.
} 
confundir direitos de aprendizagem escolar e formação crítica com mecanismos de doutrinação, reclamando valores religiosos dos alunos e de suas famílias. Em verdade, essa ameaça mostra a fragilidade com a qual as relações entre o privado e o público vêm sendo tratadas em nosso país.

O exame do processo de implantação de lei obrigando o ensino religioso na forma confessional nas escolas estaduais do Rio de Janeiro há exatos $16 \operatorname{anos}^{2}$ (Lei 3.459/2000) permite encontrar conexões de um passado não distante com o avanço do conservadorismo explícito no PL 867 do "Programa Escola Sem Partido" dos dias atuais. Utilizando como fonte cartas dos leitores do jornal $O$ Globo ${ }^{3}$, além de outros pronunciamentos da mídia ao tempo da tramitação e aprovação daquela lei, essa problemática é colocada em diálogo com textos acadêmicos que inventariam e buscam entender as tensões entre evolução e criacionismo em diversas instâncias educativas, vividas por professores e alunos. Esse exame dá margem a compreender a produção curricular como arena de disputa, como uma construção sociocultural imersa em valores e interesses de diferentes grupos sociais.

O caso do Rio de Janeiro não é isolado nem circunscrito a uma história particular, haja vista a reverberação provocada em outros estados e municípios desde então. A polêmica do ensino religioso nas escolas públicas brasileiras aparece associada a novos elementos, incluindo pela primeira vez discussões ligadas não apenas à cidadania e à liberdade religiosa, mas também ao confronto - relativamente novo no Brasil e com enorme potencial de crescimento - entre os pontos de vista criacionista e evolucionista. Este cenário resulta da formação de novas alianças entre grupos religiosos disputando o espaço público em oposição aos defensores da laicidade (CUNHA, 2006). A propósito, nos dias atuais, o Movimento Escola Sem Partido ${ }^{4}$, instância de sustentação para a aprovação do PL 867/2015, vem identificando outros sujeitos dessas alianças e seus pertencimentos religiosos e político-partidários.

Sobretudo, apresenta-se à sociedade brasileira um potencial de agravamento significativo diante das mais recentes transformações ocorridas no cenário religioso nacional (JACOB et al., 2003) e do que apontam os resultados de pesquisas recentes como a do Datafolha, constatando que $25 \%$ da população não se referem à teoria evolutiva quando explicam a origem dos seres humanos, adotando explicações criacionistas, ou seja, de que Deus nos criou da maneira como somos hoje em algum momento nos últimos 10 mil anos. Apenas 8\% dos brasileiros explicam a origem da espécie humana a partir de espécies ancestrais independentemente de uma criação divina direta (DATAFOLHA, 2010).

Com certeza esse quadro, tonificado pelos defensores da aprovação do PL 867, representados pelo Movimento Escola Sem Partido, já se traduz e se traduzirá nos próximos anos em uma realidade cada vez mais comum a se somar às demais já enfrentadas por professores de Ciências e Biologia nas salas de aula da educação básica e mesmo no ensino superior. Para reunir condições de lidar melhor com este problema é preciso entender o processo com mais

\footnotetext{
${ }^{2}$ Disponível em: <http://www.camara.gov.br/sileg/integras/1317168.pdf>. Acesso em: 6 out. 2016.

${ }^{3} \mathrm{O}$ governador Anthony Garotinho sancionou no dia 14 de setembro de 2000 a lei 3.459 que obriga o ensino religioso na rede pública estadual na forma confessional. O projeto original era do ex-deputado Carlos Dias (PPB), que facultava aos pais o direito de escolher a orientação religiosa a ser lecionada aos filhos. Carlos Dias era direta e publicamente vinculado a autoridades e grupos da Igreja Católica no Rio de Janeiro e foi com o apoio deles que apresentou seu projeto de lei. O texto da lei está disponível em: <http://gov-rj.jusbrasil.com.br/ legislacao/136999/lei-3459-00>. Acesso em: 6 out. 2016.

${ }^{4}$ Matérias do jornal O Globo sobre a aprovação do Ensino Religioso (ER) em escolas públicas no Estado do Rio de Janeiro, no período de 01 de janeiro de 1997 a 31 de dezembro de 2002. Inquestionavelmente esse periódico confere legitimidade ao estudo em virtude de sua grande circulação no Estado do Rio de Janeiro.
} 
profundidade, investigando mais detalhadamente as razões envolvidas no crescimento desse fenômeno no Brasil nos últimos anos, as quais certamente resultam de um quadro multifatorial. Nesse sentido, trabalhos como os de Dorvillé (2010), El-Hani e Sepulveda (2010), e Sepulveda e El-Hani (2004) são certamente cada vez mais necessários por permitirem uma melhor compreensão do modo como opera o pensamento de alguns desses estudantes e de suas motivações.

Mesmo sem focalizar detidamente como lidar com essa compreensão, podemos apontar de antemão dois pontos norteadores iniciais. Concordando com Martins (2013), o primeiro é a necessidade de reforço, por parte de cientistas e professores de Ciências e Biologia, do conjunto de práticas relacionadas à divulgação científica, empregando os mais diversos recursos. O segundo é o de reforçar também um entendimento da natureza da atividade científica, procurando caracterizar seus modos de ação, limites e possibilidades, mesmo entendendo todas as dificuldades inerentes à sua demarcação. Ainda que admitamos não ser possível reduzir as disciplinas escolares às científicas (MARANDINO; SELLES; FERREIRA, 2011), não nos cabe secundarizar as Ciências Biológicas como uma das referências norteadoras do ensino de evolução. Por meio de um trabalho construído nessas bases, os alunos poderão ter mais chances de entender os mecanismos da ciência, diferenciando-a de outras lógicas e entendendo que a mesma opera a partir de um materialismo metodológico que não deve ser confundido como uma ontologia materialista (SCOT'T, 2004). A partir do estudo de exemplos da história do desenvolvimento científico, os alunos podem entender de modo mais claro que processos estão envolvidos na sua construção e o que não é válido em sua lógica operacional.

Certamente não se tem como pretensão afirmar como o professor deve se posicionar em sala de aula em relação aos conflitos provocados pela contradição explícita entre teoria evolutiva e o criacionismo, ou como o ensino de Biologia pode de fato lidar com tais aspectos pseudocientíficos, nem tampouco antecipar como a formação de professores de Biologia deve incorporar os resultados descritos na produção acadêmica acerca desses conflitos, para não incorrer no risco de se equiparar aos moldes dogmáticos os quais pretende combater. No entanto, as ameaças provocadas pela onda neoconservadora demandam respostas apoiadas em estudos acadêmicos que subsidiem os posicionamentos políticos nos diversos fóruns aos quais se exige a presença dos educadores. A inclusão do ensino religioso nas Diretrizes Curriculares Nacionais da Educação Básica ${ }^{5}$, bem como no texto preliminar das Bases Nacionais Comuns Curriculares ${ }^{6}$, é um dos exemplos que ilustram a abrangência e a pertinência curricular do debate que se propõe a enfrentar. Tampouco essa discussão pode deixar de se contrapor ao Movimento Escola Sem Partido, cujas reivindicações incluem a rejeição ao ensino da evolução biológica e a defesa da "liberdade" das famílias e dos alunos acerca deste e de outros conteúdos curriculares, aprofundando a ingerência do privado na educação pública. Associações científicas ${ }^{7}$ têm enfaticamente se posicionado contra tal estratégia conservadora, em consonância com argumentos elencados neste texto.

\footnotetext{
${ }^{5}$ Disponível em: <http://www.escolasempartido.org>. Acesso em: 6 out. 2016.

${ }^{6}$ BRASIL. Ministério da Educação. Diretrizes curriculares nacionais da educação básica. Brasília, 2013. Disponível em: <http://portal.mec.gov.br/index.php?option=com_docman\&view=download\&alias=13448-diretrizescuriculares-nacionais-2013-pdf\&Itemid=30192>. Acesso em: 6 out. 2016.

${ }^{7}$ Disponível em: <http://basenacionalcomum.mec.gov.br/>. Acesso em: 6 out. 2016.

Dentre elas, destacamos o manifesto e a moção de repúdio votada na Assembleia Geral da Associação Brasileira de Pesquisa em Educação em Ciências (ABRAPEC) no X ENPEC realizado em novembro de 2015 (disponível em: www.abrapecnet.org.br ou na página da Associação Brasileira de Ensino de Biologia - SBEnBio - www. sbenbio.org.br). De igual modo, o posicionamento da Associação Nacional de Pesquisadores Universitários de História expressa sua oposição ao Movimento Escola Sem Partido está disponível em: <https:// dl.dropboxusercontent.com/u/34634009/Carta\%20de\%20Rep \%C3\%BAdio\%20ESP.pdf>.
} 
Cabe reavivar uma oportuna reflexão tecida por Michael Apple há mais de 20 anos. Em concordância com sua análise podemos compreender que desde a década de 1990, operando em associação ao neoliberalismo - ainda que distinto deste -, o avanço do neoconservadorismo em escala mundial (APPLE, 1994) se refina e se afirma na sociedade brasileira. Em seu artigo, elaborado em 1992 e publicado no Brasil em 1994, Apple antecipa um debate que, naquele momento, talvez tenha parecido descontextualizado à realidade social e política do Brasil. Afinal, vivíamos um período de democratização que pretendia exorcizar os traumas da ditadura e se opunha às armadilhas ideológicas do governo de direita que havia se encerrado, tornando difícil encontrar, na análise do autor, paralelismos com o Brasil, entendendo-a apenas como pertinente à realidade estadunidense. Entretanto, o artigo de Apple (1994, p. 69) contribui para a compreensão dos complexos meandros que formam o que ele denomina de "restauração conservadora" na disputa sobre o controle da escola. De um lado, a ideologia da "economia de mercado" que reduz a ação do Estado, recomenda a privatização, a livre escolha e defende a utilização da metodologia empresarial aos professores e alunos, exaltando a competição e produzindo ranqueamentos, por meio da vinculação direta entre currículo mínimo e sistema de avaliação. De outro lado, o neoconservadorismo requer um estado forte para agir sobre o controle dos sujeitos, defendendo a "liberdade", desde que sejam reforçados os valores da família e da religião, sob o argumento de recuperação moral da sociedade.

No Brasil, como já referido, demonstram a atualidade da análise de Apple: a emergência de políticas de currículo e de avaliação que têm assolado a comunidade educacional nas últimas duas décadas, com ameaça à autonomia docente, a crescente ingerência de interesses privados e conservadores como o Movimento Escola Sem Partido, o combate ao que é intencionalmente denominado "ideologia de gênero", bem como a defesa da narrativa criacionista em oposição ao ensino de evolução nas aulas de Ciências e Biologia demonstram a atualidade da análise de Apple. Sem dúvida, num tempo como o que vivemos cabe aos docentes e aos educadores indagar acerca de seu trabalho e de seu papel; cabe à comunidade acadêmica se posicionar criticamente. Ao sugerir a persistência do conservadorismo que se reinventa, o exame das relações provocadas pelo ensino religioso no estado do Rio de Janeiro se atualiza e se coloca ao lado do compromisso de fornecer elementos que qualifiquem o debate nacional em bases políticas e acadêmicas.

Sandra Escovedo Selles

Universidade Federal Fluminense (UFF), Faculdade de Educação Associação Brasileira de Pesquisa em Educação em Ciências (ABRAPEC) e-mail: escovedoselles@gmail.com 


\section{Referências}

APPLE, M. A política do conhecimento oficial: faz sentido a idéia de um currículo nacional? In: MOREIRA, A. F. B.; SILVA, T. T. Currículo, cultura e sociedade. São Paulo: Cortez, 1994. p. 59-91.

CUNHA, L. A. Autonomização do campo educacional: efeitos do e no ensino religioso. Revista Contemporânea de Educação, Rio de Janeiro, n. 2, p. 1-15, 2006. Disponível em: < http://www.fe.ufrj.br/ artigos/n2/numero2-lacunha.pdf >. Acesso em: 6 out. 2016.

DATAFOLHA. Pesquisa de opinião pública sobre o criacionismo. Folha de São Paulo, São Paulo, n. 29.584, 2 abr. 2010.

DORVILLÉ, L. F. M. Religião, escola e ciência: conflitos e tensões nas visões de mundo de alunos de uma licenciatura em ciências biológicas. 2010. 357 f. Tese (Doutorado) - Universidade Federal Fluminense, Niteroi, 2010.

EL-HANI, C. N.; SEPULVEDA, C. The relationship between science and religion in the education of protestant biology preservice teachers in a Brazilian university. Cultural Studies of Science Education, Dordrecht, v. 5, n. 1, p. 103-125, 2010.

JACOB, C. R. et al. Atlas da filiação religiosa e indicadores sociais no Brasil. Rio de Janeiro: Ed. PUCRIO; São Paulo: Loyola, 2003

MARANDINO, M.; SELLES, S. E.; FERREIRA, M. S. Ensino de biologia: histórias e práticas em diferentes espaços educativos. São Paulo: Cortez, 2011.

MARTINS, M. V. M. Quando uma sociologia da ciência se faz necessária: aspectos contemporâneos do embate entre criacionistas e evolucionistas. Filosofia e História da Biologia, São Paulo, v. 8, n. 2, p. 279-299, 2013. Disponível em: < http://www.abfhib.org/FHB/ FHB-08-2/FHB-8-2-07-Mauricio-Vieira-Martins.pdf>. Acesso em: 6 out. 2016.

SCOTT, E. C. Evolution versus creationism: an introduction. Berkeley: University of California Press, 2004.

SEPULVEDA, C. A. S.; EL-HANI, C. N. Quando visões de mundo se encontram: religião e ciência na trajetória de formação de alunos protestantes de uma licenciatura em ciências biológicas. Investigações em Ensino de Ciências, Porto Alegre, v. 9, n. 2, p. 137-175, 2004. 